\title{
POEMA CORPO: O CORPO POEMA
}

BODY POEM: POEM BODY

\author{
Wanderlan Alves \\ Universidade Estadual da Paraíba \\ Campina Grande, PB - Brasil \\ ORCID 0000-0003-4146-2335
}

\section{Resumo}

Neste artigo, analisamos a exposição fotográfica Corpo-poema, a partir das noçôes de campo expandido, pós-autonomia e inespecificidade, visando a compreender os processos criativos e vivenciais da arte, no projeto em questão, e os modos pelos quais o trabalho potencializa a liberação dos corpos femininos, assim como a restituição da literatura e do corpo aos espaços públicos. Num processo em que corpo e palavra são refuncionalizados, ambos desestabilizam a instituiçáo literária e colaboram para um sentido de ampliação do campo da literatura contemporânea brasileira.

Palavras-chave: pós-autonomia; campo expandido; literatura; fotografia; arte contemporânea.

\begin{abstract}
This article discusses the photographic exposition titled Corpo-poema [Body-poem], drawing on concepts such as expanded field, post autonomy and unspecificity, seeking to understand both the creative and experiential artistic processes involved in this project, and the ways in which this work promotes the liberation of women's bodies, as well as the restitution of literature and the body in public spaces. In a process in which body and word are repurposed, they both unsettle the literary institution and contribute to expanding the field of Brazilian contemporary literature.
\end{abstract}

Keywords: post autonomy; expanded field; literature; photography; contemporary art.

\section{Resumen}

En este artículo analizamos la exposición fotográfica Corpo-poema [Cuerpo-poema] desde las nociones de campo expansivo, posautonomía e inespecificidad, intentando comprender los procesos creativos y de vida en el arte en dicho proyecto, además de los modos por los que este trabajo potencia la liberación de los cuerpos femeninos, así como la restitución de la literatura y del cuerpo a los espacios públicos. En este proceso, en el que el cuerpo y la palabra se refuncionalizan, ambos desestabilizan la institución literaria y colaboran para una reestructuración y ampliación del campo de la literatura brasileña contemporánea.

Palabras-clave: posautonomía; campo expansivo; literatura; fotografía; arte contemporáneo. 
[...] su humanidad que es ante todo la del ser de la escritura

(Severo Sarduy, Escrito sobre un cuerpo, 1999, p. 1137)

Nos dias atuais, a epígrafe acima pode chocar um pouco o leitor, por sua aparente redução da textualidade à escritura, e soar talvez anacrônica, especialmente se se considerar o chamado retorno do autor na literatura e na arte contemporâneas, para empregarmos a expressão de Klinger (2012). O ensaio de Sarduy foi escrito em 1968/69, mesma época em que, não por coincidência, Roland Barthes publica o seu sobre a morte do autor, em si mesmo táo polêmico e, ao mesmo tempo, seminal para os estudos que o sucederam a respeito da autoria e do papel fundamental que passa a exercer o leitor na literatura e na arte, a partir de então. Por sua vez, nem Barthes nem Sarduy negaram o autor em suas obras de fato - no caso de Barthes, esse processo de retorno do autor se acentuaria até aproximar-se, inclusive, da autobiografia ou da autoficção em seus últimos escritos, como mostra Figueiredo (2015); a obra do cubano, por sua vez, está plasmada de elementos biográficos e autoficcionais do começo ao fim, em todos os gêneros que ele praticou.

Mas o fragmento poderia apontar hoje, também, para outros matizes (não menos importantes) do papel político da escritura: numa época em que a arte e o tecido social estão tâo marcados pelas disputas de territórios, lugares de fala, representaçóes e representatividades, nem sempre o falar sobre constitui-se numa transgressão potencializadora de subjetividade(s). Ao contrário, por vezes, apenas alimenta mais um nicho que o mercado explora comercialmente - a esse respeito, note-se, por exemplo, a percepção imediata do potencial mercadológico que o discurso de Ruffato em Frankfurt em 2013 abriu (ALVES, 2016) - e converte um determinado movimento em agente do sistema econômico, simbólico ou discursivo subsumido ao capital. É algo que se nota, com muita frequência, em relação às chamadas minorias, no campo artístico-literário ou, mesmo, político. De certo modo, a sociedade burguesa não só tolera, mas até se entretém com esses discursos que afirmam, discutem e condenam a exploração, a coisificação, o machismo, o sexismo, o racismo, etc. Por mais que procurem marcar uma distância crítica cuja validade se reconhece 
numa perspectiva ética, tais discursos acabam confirmando, por vezes, os princípios de funcionamento dessa sociedade que combatem. É por isso que são aceitos, desde que ocupem seu lugar de marginal e periférico - lugares também marcados por estratificaçóes internas.

Nesse contexto, o excerto de Sarduy pode apontar para uma potência da escritura, não como redução da arte à materialidade ou ao significante, mas como uma espécie de dobradiça que, ao dobrar a materialidade escritural sobre si mesma, é capaz de colocar o objeto estético como sendo seu primeiro referente para, então, situar novamente a discussão acerca dos lugares discursivos, das disputas, da obra, da autoria, não mais de uma perspectiva da representação - ou de um regime representativo cujas regras circunscrevem um sistema fechado (RANCIÈRE, 2005) -, mas de uma perspectiva que faça da oposição entre um fora e um dentro (que está na base, por exemplo, de uma classificação como literatura/escrita feminina) um dentrofora que se torne o seu próprio potencial de resistência, ao transtornar os princípios classificatórios.

Se operarmos um retorno, mas como uma volta para adiante, para empregar uma expressão de Sandra Contreras (1996) originalmente usada em outro contexto, ao papel da materialidade da escritura, para pensar seu potencial de crítica e resistência na arte, talvez possamos avançar na discussão a respeito tanto da estética quanto da ética na literatura e na arte contemporâneas, haja vista a condição de medium-de-reflexão (BENJAMIN, 1999) da linguagem artística dar a ver aquilo que, segundo Sarduy, a burguesia não tolera, aliás, não só ela, mas crentes e ateus, capitalistas e comunistas, aristocratas e proletários, como ironiza o escritor cubano: "[...] lo que la 'saca de quicio' es la idea de que el pensamento pueda pensar sobre el pensamiento, de que el lenguaje pueda hablar del lenguaje, de que un autor no escriba sobre algo, sino escriba algo" (SARDUY, 1999, p. 1129), justamente pela opacidade ou o espessamento operado na linguagem. Quando tecida desse modo, a arte dos outros (mulheres, negros, gays, periferias, etc.) implode as oposiçóes entre o alto e o baixo, mina a força dessas dicotomias enquanto valores que orientam os discursos sobre a arte, e adentra, de fato, o campo ampliado das disputas e contestaçóes territoriais - que não deixam de existir, no tecido social, mas normalmente figuram nele de modo naturalizado, enquanto mito ou 
fala despersonalizada que se apresenta como sendo desde sempre assim (BARTHES, 1972) e tenta ser invisível. É justamente esse movimento de instabilidade provocada em sua própria materialidade que faz de Corpo-poema não só uma obra de arte, mas uma prática artística contemporânea.

Fruto do trabalho do Ariel Coletivo Literário ${ }^{1}$, Corpo-poema é um projeto organizado em torno do corpo feminino, suas formas, curvas, fissuras, marcas e dobras, assim como dos discursos socialmente atrelados a ele, mas também suas subversôes e inflexōes na literatura. O projeto consiste em 18 realizaçóes fotográficas de mulheres nuas cujos corpos aparecem plasmados de frases, versos ou fragmentos de textos literários, originalmente oriundos do repertório do sarau Dama da noite, ideologicamente engajado ao feminismo. Quanto a isso, como observa Costa Júnior em introdução a uma entrevista com a idealizadora e a fotógrafa do projeto, Thays Albuquerque e Marília Cacho, respectivamente, trata-se de "[...] uma arte que ecoa o grito de reivindicaçáo e de pautas feministas, em um mundo enviesado por um discurso machista, misógino e preconceituoso" (COSTA JÚNIOR, 2018).

Enquanto realização artística, por sua vez, Corpo-poema é uma exposição que opera como instalaçáo, visto que, ao longo de sua trajetória, por vezes em razão de questôes logísticas e operacionais, foi ganhando contornos e configuraçôes particulares em cada uma de suas realizaçóes. Como nos explicou Thays Albuquerque numa conversa, o primeiro ensaio fotográfico foi realizado em 2015, e contém 18 fotografias em tamanho $42 \mathrm{~cm} \times 63 \mathrm{~cm}$, tendo sido exposto até recentemente. A segunda ediçáo fotográfica, também com nova configuração, acaba de ser inaugurada na Usina Cultural Energisa, em Joáo Pessoa, onde fica de 05 abril a 05 de maio de 2018, numa realizaçáo do Ministério da Cultura (via Lei Rouanet), com patrocínio da Energisa.

1 Grupo formado por estudantes, artistas e intelectuais, em Campina Grande-PB, para a prática, a vivência e a divulgação da arte, a partir de saraus, exposiçóes e performances. Atualmente, é composto basicamente por mulheres. O grupo pode ser acompanhado em redes sociais como o Facebook e o Instagram, assim como na exposição de que tratamos neste texto. 
A primeira edição, de cujo ensaio nos ocupamos aqui, foi exposta no Museu de Arte Contemporânea da Universidade Estadual da Paraíba, em 2015, única ocasião em que todas as 18 fotografias foram expostas formando a narrativa completa inicialmente idealizada para o ensaio. Em seguida, foi exposta na Virada Cultural de Sousa-PB (edição 2016) em nova montagem, dessa vez com 4 fotografias em tamanho original e $14 \mathrm{em}$ pequenos formatos. Em 2017, foi exposta no "Corredor galeria" do Centro Cultural Banco do Nordeste, também em Sousa, onde, por limitaçóes do espaço, figuraram apenas 12 fotografias, numa montagem diferente das anteriores. Integrando uma exposição coletiva realizada em Campina Grande, como parte do projeto de curta-metragem Não mais!', dirigido por Rafaella Gaião, Corpo-poema apresentou-se com 6 fotografias, dessa vez numa configuração articulada a outros projetos artísticos. E apresentou-se, por fim, no Centro Cultural Banco do Nordeste Cariri, em Juazeiro do Norte-CE, onde está aberta e 15 fotografias estão expostas. Além disso, uma das fotografias do trabalho integrou a Rizoma mostra nômade multimidia \& internacional de arte contemporânea, que aconteceu em Pelotas-RS, em 2017. De modo semelhante, o próprio sarau Dama da noite, que oferece a base literária ou verbal à exposição, foi passando por inúmeras alteraçóes ou reformulaçóes, desde sua primeira apresentação, em março de 2015.

Desse modo, Corpo-poema potencializou, ao longo do tempo, toda uma mise-en-scène que se recria a cada vez que se redesenha em novos espaços e ocasióes, atualizando também sua própria narrativa, que passa pelo trauma, a dor e estigmas associados histórica e socialmente ao corpo feminino e à mulher, visando a uma ressignificação dos próprios corpos. Nesse sentido, a performance também figura em alguma medida, no horizonte do trabalho, seja pelo irrepetível de cada uma de suas versóes, seja porque os textos que se inscrevem nos corpos nus das mulheres já circulavam, ligados ao projeto do coletivo literário, na oralidade dos saraus realizados pelo grupo. Como no verso de "Com licença poética", de Adélia Prado, que diz "mulher é desdobrável. Eu sou” e que constitui a inscrição no corpo nu numa das fotografias, Corpo-poema se mostra desdobrável, flexível, um corpo (físico, literário, visual e material), que se dobra e desdobra sobre si ou sobre os espaços por onde se insinua, contraindo, a cada vez, 
novas relaçóes entre suas partes e apresentando outras nuances, com o que os corpos (a instalação, as fotografias, os corpos humanos) vão se desnaturalizando a cada vez que se enunciam ou se reciclam.

Tal procedimento constitui-se no fundamento concreto da própria proposta, uma vez que o objetivo central dessa exposição/ instalação é desmitificar e desnaturalizar a excessiva sexualização do corpo feminino, conforme ele circula, tradicionalmente, nos meios de comunicação e na publicidade, a partir de agenciamentos que coisificam a mulher, reduzindo-a a objeto erótico - como é evidente em propagandas de carros e bebidas alcoólicas, por exemplo. Nesse sentido, vislumbra-se em Corpo-poema "[...] una voluntad de imbricar las prácticas literarias en la convivencia de la experiencia contemporánea” (GARRAMUÑO, 2009, p. 3). Experiência que faz parte do real cotidiano, tanto aquele vivenciado pelas mulheres em casa, no trabalho ou na rua, quanto o que circula na TV, na internet, nas redes sociais, etc., e que está na base da imaginação pública, que ainda trata a mulher como sendo inferior ao homem, sentimental, sensível ou frágil.

Há, nessa prática com a arte, a irrupção de uma potência da comunidade, no trabalho tanto do Ariel Coletivo Literário quanto de Corpo-poema, que faz frente às duas principais esferas de ação e regulação dos afetos pelo sistema produtivo, no tecido social - as relaçóes comerciais e a comunicação, como lembram Negri e Hardt (1999). Ainda que a complexa rede de relaçóes envolvendo os conceitos de multidão e comunidade possa tornar questionável a hipótese desses dois intelectuais sobre o poder de ação dos afetos para a aproximação dos indivíduos, no projeto em análise é justamente um envolvimento de características comunitárias que surge por meio da rede de afetos que se desenha em Corpo-poema. No primeiro ensaio, de certo modo pautado numa lógica da intimidade, na medida em que as modelos são membros do coletivo literário e, portanto, já se conheciam e conviviam com frequência, os afetos se manifestam nas próprias afinidades (eletivas) que as levam a integrar ambos os projetos juntas, lendo literatura, realizando as performances em saraus e compartilhando experiências de escrita. Conforme contou-nos sua idealizadora, para o segundo ensaio, recém-lançado, houve uma ampliação do número de participantes, quase dobrou o número de modelos, e entre elas 
há mulheres mais velhas do que a média etária da primeira edição, inclusive a mãe de uma delas.

O procedimento de pré-produção, para ambos os ensaios, confirma essa rede de afetos e solidariedades: coletivamente, as mulheres envolvidas no projeto escolhem os trechos dos textos literários que figurarão nas fotografias, contam-se umas às outras o porquê de suas escolhas ou sugestôes, assim como decidem onde a inscrição será feita no corpo, a posição dos textos, ângulos, etc. São também elas que escrevem, nos corpos umas das outras, os respectivos trechos literários. Nesse sentido, a pré-produção fotográfica constitui-se num lugar (discursivo e físico-corporal) que permite às integrantes se conhecerem e, de certo modo, reconhecerem-se enquanto eu e enquanto outro, numa lógica de incompletude que não só acolhe a diferença, mas faz dela o elemento que norteia seus vínculos afetivos (BUTLER, 2015). Literatura e fotografia emergem, portanto, como sendo constitutivas de um espaço de comunicação e convivência.

Como se nota, trata-se de uma concepçáo da arte - e especialmente da literatura e da fotografia - que não se limita à especificidade dos meios e, além disso, instaura um regime prático como fundamento de sua própria existência. Promove-se um deslocamento do foco no produto final, típico da arte moderna centrada na autorreferencialidade da obra como produto acabado - pois aqui não há um produto final, mas apenas etapas ou fases de um projeto que está em constante reconfiguração -, para uma valorização da arte como instância processual cujo espessamento supera aquilo que, material e concretamente, se deixa fixar no instantâneo fotográfico que, depois, como fotografia, será oferecido ao espectador. Há todo um rol de pequenos eventos, falas, situaçóes e contatos corporais que estão simultaneamente dentrofora do Corpo-poema. Estão fora, porque não se deixam captar facilmente pelo visitante da exposiçấo, por quem contempla as fotografias, exceto através da imaginação, mas estão enlaçadas em seu interior- as fotografias apontam para tais vivências, tais vivências se encontram nas fotografias, não na sua totalidade, mas naqueles punctuns plasmados de afetos e capazes de criar sínteses-aberturas nas imagens fotográficas e, deste modo, reconectá-las à vida.

Nesse dentrofora cabe tudo aquilo que é da ordem da experiência, da experimentação, da dissonância, que se situa além do 
legível enquanto incompletude necessária à própria constituição das condiçóes de reconhecimento do eu e do outro tanto dos membros do grupo, no projeto, quanto dos espectadores da exposição, que se tornam copartícipes da proposta, também enlaçados no funcionamento do trabalho enquanto instalaçáo, que, como dissemos acima, se atualiza a cada vez que seus dispositivos são acionados, novos visitantes aparecem ou outros espaços integram-se à sua estrutura.

No plano estético, tais lacunas podem ser tratadas num campo expandido. A proposta de se pensar a arte a partir de um campo expandido não é recente, e ganhou visibilidade em 1979, quando Rosalind Krauss (2008) a sugeriu como alternativa para teorizar os caminhos que a escultura tinha tomado, no contexto da crise do modernismo, apresentando-se de tal modo distanciada das noçóes tradicionais de escultura, que somente a partir de uma ampliação do conceito seria possível tratá-la como tal. Para Krauss, esse fora do campo escultórico equivalia, naquele momento, ao pós-modernismo. A partir dos anos 1990, ela passa a tratar a questão como sendo pertinente à "condição pós-medium" (BRIZUELA, 2014) da arte contemporânea. Se deixarmos de lado esse aspecto datado de sua reflexão - natural, quando se tem em mente a própria historicidade de um conceito -, assim como a configuração estruturalista de sua proposta inicial, veremos que a noção de um campo expandido tem sido importante para os caminhos que algumas vertentes da literatura e da arte seguiram desde então em várias partes do mundo, ainda que, aqui, vamos nos deter no Brasil ou, eventualmente, na América Latina. Como contextualiza Natalia Brizuela,

[...] o projeto da literatura vindoura, do que chamamos de literatura contemporânea, se situa, nas palavras de Bellatin, "nas fronteiras" entre a literatura e as outras artes, fazendo com que a escrita "assuma a categoria de prática artística”. Nessa zona porosa do limite, da fronteira, espaço e momento sempre de contágio, de contaminação e de metamorfose, tanto a literatura se transforma em outras artes como as demais artes são potencialmente transformadas em literatura (BRIZUELA, 2014, p. 13-14). 
É esse lugar da arte como sendo dissonante e inacabado que problematiza qualquer concepçáo estética centrada em lugares pré-definidos para os objetos estéticos. Sua configuração liminar a situa numa zona flexível, em que o reconhecimento do objeto de arte ocorre, por vezes, náo porque ele segue um conjunto de regras determinadas para sua constituição, mas porque, em meio ao jogo de tensōes entre arte e não arte, natural e não natural etc., se produzem cruzamentos que potencializam a arte até mesmo naquilo que aparentemente seria o seu contrário ou o fora de si. Essa tensão - que Adorno (1982) argumenta ser condiçấo sine qua non da própria arte - abriu caminhos para o desenvolvimento dessas experiências que, na arte contemporânea, constituem o que Flora Sussekind (2013) tem chamado de objetos verbais não identificados, Josefina Ludmer (2007; 2010) de literaturas pós-autônomas e Florencia Garramuño (2014) de artes inespecíficas. Como quer que o chamemos, trata-se de um movimento entrópico que produz um repensar sobre a arte, sua história e seus usos na cultura moderna, ao mesmo tempo em que aponta para a emergência (LADDAGA, 2006) - como aquilo que emerge, mas também como o que é urgente - de novos usos e práticas para o campo estético, capazes de responder de modo consequente às demandas sociais, políticas e culturais de nossa época, restituindo-lhe, por vezes, espaços e papéis silenciados por uma política totalmente centrada na concepção de autonomia da literatura e da arte, ao longo dos últimos dois séculos, aproximadamente.

Em Corpo-poema se nota um procedimento de restituição centrado no corpo, como lugar da escrita e da literatura. Um traço característico da literatura moderna, em seu percurso de autonomizaçáo, foi seu afastamento da vida comunitária enquanto prática social - cada vez mais reduzida aos eventos privados ou normatizados, como na escola - e seu silenciamento e restrição à página do livro, como observa Foucault (2007). Nesse percurso, náo lhe sobrou alternativa, a não ser afirmar a si mesma, ainda que em sua mudez, escondida dentro do livro - paradoxalmente, é a decorrente desse mesmo contexto a exploraçáa do signo em suas diversas possibilidades de sentido (sonoro, visual, semântico, morfossintático etc.). O livro se tornou, inclusive, o lugar emblemático do literário, espécie de cela que o ressacralizaria (outro paradoxo, haja vista a chamada crise da aura), mas 
também o protegeria das transformaçóes que mudariam para sempre o lugar da literatura, do artista e da própria arte - a era industrial, a linha de montagem, a cultura de massa, etc. Tal processo pouco a pouco separou a literatura - privada, silenciosa, à espera do leitor isolado - da vida e do corpo, suscetíveis ao contato com as miudezas do cotidiano e à regulação, na dinâmica social, na intimidade, no âmbito dos prazeres (FOUCAULT, 1988).

Em sua configuração que articula a voz e a performance, nos saraus, ao texto e ao corpo, nas fotografias, Corpo-poema restitui à literatura esse lugar do/no corpo como sendo também o seu. A pele não figura como simples metáfora da folha de papel, mas como a própria superfície em que a letra se inscreve e se escreve para dar-se a ver e colocar-se em contato com o mundo. O procedimento é de restituição, pois devolve a escrita ao corpo, ao couro, à pele - por sua vez, associando-se à liberação da escrita para outros lugares, em razão de sua facilidade de manejo e transporte (qual o pergaminho). Por essa via, opera-se uma fusão de temporalidades da/na literatura; todos os seus tempos e toda a sua história se colocam para o diálogo, não como abstraçáo ou metáfora, mas concretamente no corpo da escritura. Contraem-se, ainda, outras relaçóes simbólicas importantes para o projeto, na medida em que o corpo feminino também foi modernamente silenciado, coberto e obrigado, por vezes, a esconder-se na intimidade privada, liberado apenas para o acesso de quem o detém (família, marido etc.). O paralelismo que se estabelece nessa operação de restituição, que sincroniza a escrita com o corpo, faz deste uma superfície para ser vista e lida livremente, em sua condição intimopública que define suas próprias dimensóes (altura, largura e volume) e, além disso, integra todo um sistema (de relaçóes, de sentidos e de formas) de modo dinâmico, plasmado de conflitos, vínculos (ou vincos) e história(s): "La literatura es el arte de restituir la Historia" (SARDUY, 1999, p. 432).

Enquanto corpo (físico, estético e literário) que se levanta contra seu histórico tratamento como corpse (cadáver), em Corpo-poema o corpo e a literatura implicam um campo expandido marcado por implosôes e explosóes e, consequentemente, pelas irradiaçóes supostas em qualquer movimento de dispersão. Como analisa Florencia Garramuño, 
[...] lo cierto es que la idea de un campo expansivo - con sus connotaciones de implosiones internas y de constante reformulación y ampliación - resulta tal vez más apropiada para reflexionar sobre una mutación de aquello que define lo literario en la literatura contemporánea que en su inestabilidad y ebullición atenta incluso contra la propia noción de campo como espacio estático y cerrado (GARRAMUÑO, 2009, p. 2).

Naturalmente, trata-se de uma concepção da literatura que póe em xeque o literário como algo previamente estabelecido, e tem a vantagem de acolher práticas e formas estéticas que não cabem (ou não são aceitas, por vezes) nos espaços canônicos do literário, apesar de a ruptura ser um dos signos centrais da modernidade no campo estético, como mostram Paz (1984) ou Rosenberg (1974).

É a fotografia, por sua vez, que articula esses diferentes modos e meios de criação e expressão artística em Corpo-poema. Natalia Brizuela (2014) mostra que, na América Latina, a literatura e a fotografia contraíram certas relaçóes desde o final do século XIX, e isso se intensificaria no século XX, seja no plano dos motivos dramáticos, como elementos do ambiente, ou ainda associada à magia, à morte, etc. Também ofereceria uma linguagem e uma sintaxe de que a literatura se apropriaria, especialmente após o advento das vanguardas. Mas as relaçôes entre literatura e fotografia se intensificaram sobremaneira nas últimas décadas, como se pode notar, por exemplo, pelas obras de Bernardo Carvalho, Mario Bellatin ou Ricardo Lísias, para mencionar apenas três exemplos. Não se trata da fotografia mais (ou apenas) como prova do real, quase sempre problemática na literatura, pela condição de cópia constitutiva do fotográfico, nem como ilustração, mas como conceito.

Brizuela observa que duas das tendências historicamente produtivas da relação entre a literatura e a fotografia foram (1) a dos livros que não apresentam fotografias, mas são influenciados por sua linguagem, e (2) a dos livros em que a fotografia aparece de fato. No horizonte de um campo expandido contemporâneo em que situamos, aqui, o Corpo-poema, pode-se aventar mais um tipo de relação entre essas artes: aquela que arranca ambas de seus respectivos meios e modos de construção habituais. Já falamos da saída da literatura do 
livro para o corpo. Quanto à fotografia, no entanto, o procedimento é menos evidente à primeira vista. Mas ele se deixa entrever quando se nota que as fotografias dessa exposição/instalação não são referenciais - não visam a registrar um evento nem a um viés documental - e não são própria ou exclusivamente fotografias conceituais, no sentido de partirem de determinada situação para expressar uma ideia (como ocorre frequentemente, por exemplo, na publicidade). Apesar de haver também uma ideia norteadora da produção fotográfica de Corpo-poema, que é a desnaturalização da sexualização do corpo feminino, quando vista em sua configuração plena, isto é, arranjo formado por exposição e instalaçáo a partir de corpo, texto, imagem e disposição espacial, torna-se redutor ver nas fotografias do projeto apenas a expressáo de um conceito ou uma ideia de empoderamento. Há isso também, no entanto, não se trata de mobilizar tais materiais, indivíduos e práticas como meio para expressar uma ideia, e sim de expressar a própria fisicalidade dos corpos, dos textos e das fotografias como sendo, entre outras coisas, mensagens e referentes de si mesmos.

Promove-se, com isso, a desautomatização de uma ideia de arte e de literatura pautadas num logos que se vale da língua ou de diferentes linguagens para expressar algo primordial, mais importante ou interior. Ao contrário, na exposição a superfície (os corpos, os textos sobre os corpos, a bidimensionalidade da fotografia, as fotografias nas paredes, etc.) ocupa esse lugar em que os sentidos se formulam, o que confere ao trabalho toda uma textura, uma tessitura que é necessariamente física e conceitual, ao mesmo tempo.

Tal aspecto do projeto mostra-se singularmente significativo, se considerarmos que historicamente a interioridade, quando associada ao feminino, foi posta no âmbito da sentimentalidade, do desequilíbrio e das emoçóes, e não da razão, ao passo que a hipersensibilidade e a hiperestesia foram relacionadas ao feminino como traços patológicos, como ressalta Grossman (2016). Quanto a isso, a operação desencadeada em Corpo-poema tensiona os limites e as oposiçóes estanques entre o masculino e o feminino,

[...] explora essa poeira dos signos afetivos despercebidos para muitos de nós, esses corpúsculos textuais que permitem inventar outras modalidades criadoras estranhas à habitual divisão sexual. É assim que o hipersensível 
convida a explorar territórios sutis pouco a pouco descobertos (GROSSMAN, 2016, p. 13).

Nesse sentido, a exposição/instalação porta traços barrocos ou neobarrocos, que é, aliás, o que motiva o título de nosso texto, espécie de metáfora gongorina que acusa as contaminaçóes dos elementos envolvidos na composiçáo do objeto estético que, ao se aproximarem, produzem uma espécie de dobra, prega ou espelhamento, razão por que "se o poema corpo, o corpo poema". É a fotografia que opera essa dobra ou duplicaçáo, em Corpo-poema.

Deste modo, cada uma das instâncias envolvidas (os corpos das modelos ou da própria fotografia enquanto materialidade) se refuncionaliza e também profana os corpos enquanto intimidades, e a fotografia e a literatura quanto à ideia de especificidade dos meios, convidando o leitor/espectador a "[...] transitar sus flujos, recorrer sus contactos, y, sobre todo, proponer conexiones conceptuales entre ellas" (GARRAMUÑO, 2009, p. 8). Então, pode-se especular, por exemplo, sobre as funçóes e os sentidos que o corpo e a escrita desempenham, seja nas fotografias isoladamente, seja no conjunto que formam.

Sentada sobre um banquinho semicoberto por uma espécie de tule, tecido tradicionalmente associado ao feminino e à intimidade, sobre ele o corpo nu, as mãos que cobrem a genitália: "ninguém merece ser estuprada". O fragmento é do poema "Verdade seja dita", da paulistana Mel Duarte (Figura 1). Esta fotografia lida com o corpo como lugar do abuso. As mãos, afinal, cobrem a genitália por decoro, ou estáo, na verdade, tentando protegê-la do olhar, da invasáo, da perfuraçáo, do estupro? $\mathrm{O}$ fundo branco associado ao tule the confere uma aparência de sacralidade e pureza que contrasta com a violência expressa no fragmento. Há uma duplicação ou expansắo, que é interdiscursiva, nessa fotografia. Ela convoca, num viés crítico, o tratamento geralmente sexualizado e invasivo da câmera (filmadora ou fotográfica) no enquadramento da mulher, em programas de TV, na publicidade, que tende a reduzi-la a pedaços ou partes de um corpo sexual (quase sempre bumbum, seios, virilhas etc.). 


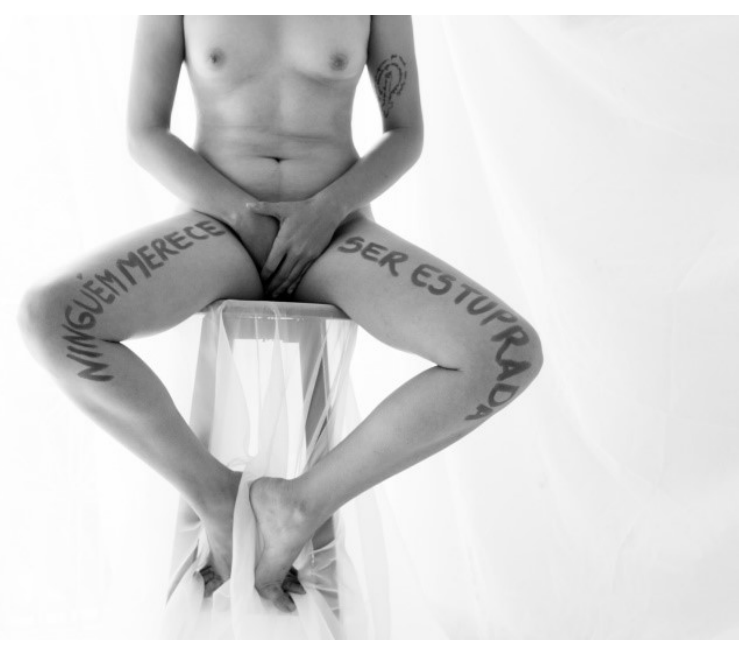

Figura 1: Fotografia que integra o projeto Corpo-poema. (Marília Cacho, 2015)

O enquadramento, nesse caso, no entanto, evita o zoom, dando conta da mulher com um todo (apesar da ausência da cabeça, que, contudo, se sobrepóe e, novamente, duplica o que se diz no fragmento, como sendo algo válido para qualquer mulher: ninguém merece ser estuprada). Paralelamente, opera-se uma intertextualidade com o processo jurídico envolvendo a deputada federal Maria do Rosário, ofendida pelo deputado de extrema direita e tendência fascista Jair Bolsonaro, que dissera em plenário que só não a estuprava porque ela não mereceria. Sob tal dicção de protesto, o corpo e a escrita passam por uma dessacralização nessa fotografia, convertendo-se numa espécie de corpo-muro onde se inscreve a escrita-pichaçáo que faz da denúncia um protesto ético. Enquanto pichação, por sua vez, aponta para uma postura de confronto, em que o periférico opera uma corrosão das instituiçóes políticas e da própria arte. $\mathrm{Na}$ mesma fotografia, outra funçáo para o corpo é clara: a de algumas de suas partes como textos (no plano da cultura), que ora são aceitos e espetacularizados, ora censurados e condenados. Como na literatura de Sarduy, nas fotografias do projeto esses pedaços de corpos-textos se juntam a outros textos, numa sobreposição que é a base sensível do objeto estético. Ao mesmo tempo, e isso as singulariza, o corpo figura como uma 
ocupação. Se o poema parece ocupar o corpo, por sua vez é o corpo que ocupa o poema com sua imago.

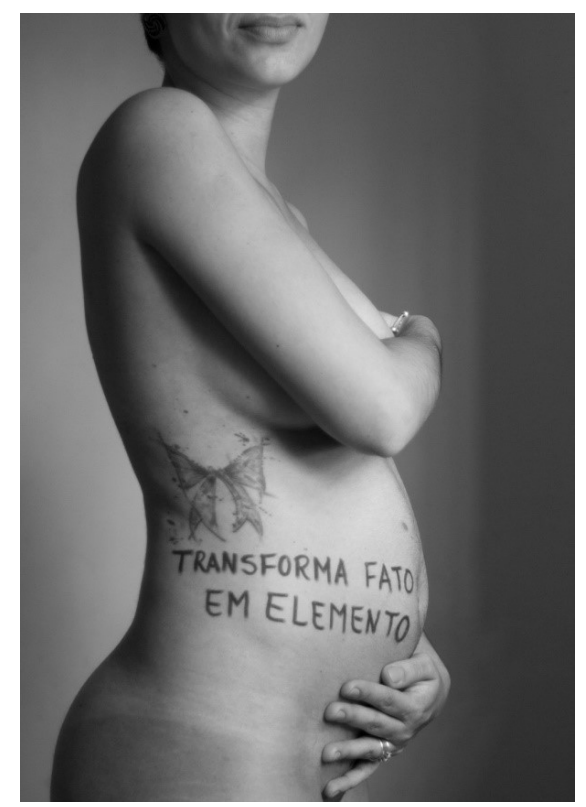

Figura 2: Fotografia que integra o projeto Corpo-poema.

(Marília Cacho, 2015)

Há em todo o processo de Corpo-poema, desde a pré-produção à produção propriamente dita e aos rearranjos em cada exposição, que poderiam constituir-se numa espécie de pós-produção, uma proposta de mudança, não a formação de uma trajetória acabada de sujeito, mas um processo de conhecimento, autoconhecimento e reconhecimento que visa à liberação dos membros do projeto e à ideia de liberdade para o leitor/espectador do trabalho. Não por acaso, como explica a idealizadora do projeto (COSTA JÚNIOR, 2018), além das leituras e discussóes entre as modelos e membros do Ariel Coletivo Literário, algumas das realizações da exposição foram acompanhadas de discussóes compartilhadas com membros de outros grupos artísticos, assim como estudiosos de questóes ligadas à mulher, ao corpo e ao feminismo. Irrompe, deste modo, a noção de que esses corpos são transformados, de que neles se inscrevem novos textos e sentidos que alteram suas formas e que podem frutificar. São, 
portanto, produtivos. Tal ideia é particularmente expressiva na Figura 2, uma vez que a escritura figura como tatuagem, pela relação que contrai com a tatuagem da modelo, e também porque a modelo está grávida. O corpo-texto-linguagem "transforma fato em elemento", trecho do poema "Aviso da lua que menstrua", de Elisa Lucinda. Enquanto materialidade e potência, literatura e corpo proliferam e produzem afecção:

La literatura es [...] un arte del tatuaje: inscribe, cifra en la masa amorfa del lenguaje informativo los verdaderos signos de la significación. Pero esta inscripción no es posible sin herida, sin pérdida. Para que la masa informativa se convierta en texto, para que la palabra comunique, el escritor tiene que tatuarla, que insertar en ella sus pictogramas. La escritura sería el arte de esos grafos, de lo pictural asumido por el discurso, pero también el arte de la proliferación. La plasticidad del signo escrito y su carácter barroco están presentes en toda literatura que no olvide su naturaleza de inscripción, eso que podría llamarse escripturalidad (SARDUY, 1999, p. 1154).

A transformação, como se pode notar, vai se manifestando em todas as dimensóes de Corpo-poema - a cada reconfiguração para uma nova versão, nos contornos individuais e comunitários pré-produção, na sobreposição de discursos e textos das fotografias etc. -, com o que a metamorfose irrompe como sendo um traço fundamental da exposição/instalação. E a metamorfose encontra na mulher um emblema (menina, mulher, mãe, avó etc.). A noção de um campo em expansão, para pensar a literatura e as artes contemporâneas, adquire aqui mais um matiz: a própria mulher como devir, corpo livre e em expansáo. Cada experiência vivida, sentida, acumulada, trauma, prazer, dor etc., constituindo-se num grafo, numa dessas marcas que lhe integra o corpo, fazendo do mesmo, a cada dia, um outro. Nessa metamorfose que (ainda que não teleológica) busca a liberdade, no devir-mulher do Corpo-poema, nenhuma delas, nenhum desses corpos "já não cabe mais no modelo perfeito dos sonhos" (ou mitos) - parafraseando o poema de Gioconda Belli, que também figura numa das fotografias - em cujo meio se descobriram. A ironia aponta para uma série de discursos que veem na mulher um perigo (bruxas, emotivas, 
traiçoeiras, irracionais, histéricas etc.): "Há que se ter cautela com essa gente que menstrua" ("Aviso da lua que menstrua", Elisa Lucinda, inscrito numa das fotografias). No contexto de Corpo-poema, o verso aponta para o corpo como esse lugar de liberaçáo.

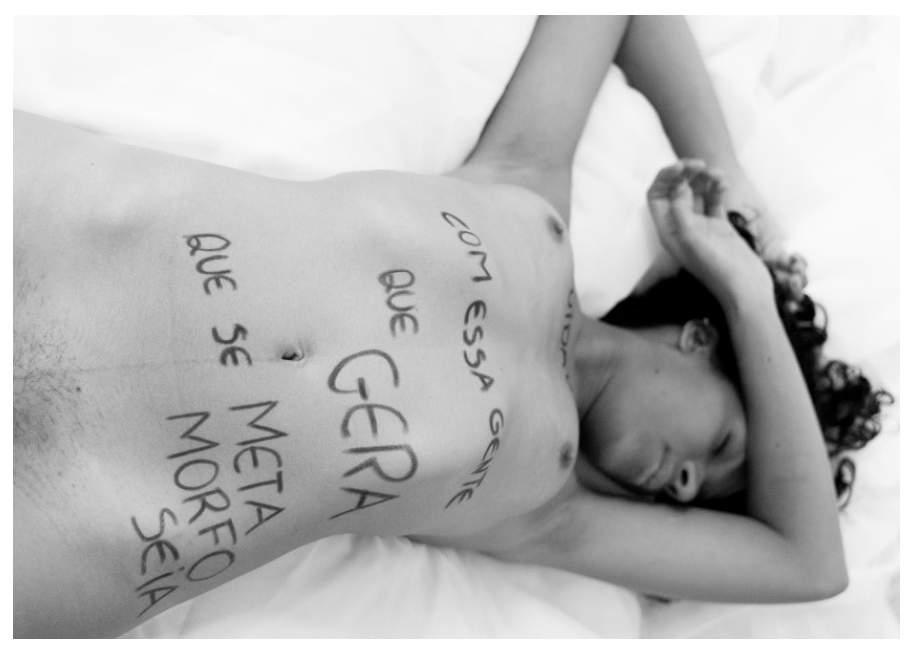

Figura 3: Fotografia que integra o projeto Corpo-poema.

(Marília Cacho, 2015)

A articulação da escrita com a fotografia acaba por promover uma escritura expandida, que é Corpo-poema. Ao potencializar conexôes e articulaçôes entre discursos, formas e texturas, os corpos, assim como os textos literários, constituem a obra de arte, que é meio de reflexão. Então, o corpo expandido (literatura + fotografia + exposiçáo + performance + instalação) emerge como duplicaçáo dos corpos (femininos) e crítica do corpo (social). Trata-se de uma operação que procura

[...] expandir o campo das nossas percepçóes e afetos, de inventar um espaço transindividual (artista e espectador, autor e leitor) que nos abra a um outro corpo de sensação, nem o meu, nem o outro, a provar, a viver, a pensar - um corpo onde nossas subjetividades - onde um tempo - se desfaçam e se recomponham, diferentes. Os corpos de escrita que eles experimentam dominam a força das pulsóes segundo uma outra lógica que náo essa da abrupta oposição binária de masculino e feminino. Eles reinventam 
corpos estranhos, decompostos e fluidos, configuraçóes relutantes ao nosso pensamento ordinário: espaço do neutro (Barthes), câmara de eco (Duras), disjunçóes inclusivas (Deleuze) (GROSSMAN, 2016, p. 21-22).

Não por acaso, a escrita dos fragmentos textuais nos corpos fotografados é feita com batom, lápis de olho e delineador, objetos expressivos de uma ideia de feminilidade e delicadeza (Figura 3). Tais objetos são desmitificados e transformados em uma espécie de prótese que dão um giro à percepção do corpo, da escrita e da própria literatura. Em Corpo-poema, náo é o corpo que ocupa o lugar do livro, nem o grafo e a tatuagem o lugar da escrita; ao contrário, cria-se um corpo-texto que acaba por sugerir que o livro é o artificioso ou artificial, que o livro é um corpo de papel. E que, portanto, mulher e escrita, assim como corpo e escritura, não só são concebíveis, mas complementares.

Se nos for permitida, então, mais uma dobra neste texto, com a que Corpo-poema náo se encerra, mas nos permite imprimir uma inflexáo a este breve experimento crítico e impor-lhe uma pausa para a escuta, cabe-nos voltar à epígrafe de que partimos: inicialmente, a ideia da humanidade equiparada à escritura podia parecer anacrônica, datada; no entanto, à medida que esse projeto escritural vai se abrindo, a escritura mostra-se núcleo em que as subjetividades se gestam, se transformam e se abrem a novas articulações, ediçôes, reconfiguraçóes. A aparente oposição entre arte e vida suposta no trecho de Sarduy também se desdobra, e vai adquirindo, no contexto de nossa leitura, condição de vida, que, por sua vez, se equipara à escritura. Se a arte resiste a alguma coisa - e parece que sim -, é justamente quando se desvencilha dos imediatismos cotidianos, é quando se encontra com a não arte, para parafrasear Rancière (2007), produzindo uma cesura que interrompe o fluxo do tempo regulado (DELEUZE, 2005) e potencializa novas inflexôes. Aquele anacronismo de que partimos, se ainda persiste, agora adquire ares de sobrevivência (DIDI-HUBERMAN, 2011). E sobreviver, em Corpo-poema, supóe entrar no jogo com o sensível e o formal. Um jogo em que se escreve no corpo, se escreve com o corpo e se escreve o próprio corpo. 


\section{Referências bibliográficas}

ADORNO, T. Teoria estética. Trad. Artur Mourão. Lisboa: Edições 70, 1982.

ALVES, W. O discurso de Luiz Ruffato em Frankfurt: polêmica, recepção inicial e paradigmas em disputa. Estudos de literatura brasileira contemporânea, n. 48, p. 149-176, 2016.

BARTHES, R. Mitologias. Trad. de Rita Buongermino e Pedro de Souza. São Paulo: Difusão Européia do Livro, 1972.

BENJAMIN, W. O conceito de crítica de arte no romantismo alemão. São Paulo: Ed. Iluminuras, 1999.

BRIZUELA, N. Depois da fotografia: uma literatura fora de si. São Paulo: Rocco, 2014.

BUTLER, J. Relatar a si mesmo: crítica da violência ética. Trad. Rogério Bettoni. São Paulo: Autêntica, 2015.

CONTRERAS, S. Las vueltas de César Aira. Actual, Mérida, n. 33, p. 91110, 1996.

COSTA JÚNIOR, J. V. L. A exposição Corpo-poema como objeto desestabilizador do literário: entrevista com Thays Albuquerque e Marília Cacho. Estudos de literatura brasileira contemporânea, n. 55, p. 135$147,2018$.

DELEUZE, G. Derrames entre el capitalismo y la esquizofrenia. Trad. Equipo editorial Cactus. Buenos Aires: Cactus, 2005.

DIDI-HUBERMAN, G. Ante el tiempo: historia del arte y anacronismo en las imágenes. 3. ed. Trad. Antonio Oviedo. Buenos Aires: Adriana Hidalgo, 2011.

FIGUEIREDO, E. Em torno de Roland Barthes: da "morte do autor" ao nascimento do leitor è volta do autor. Santa Maria: PPGL-UFSM, 2015.

FOUCAULT, M. As palavras e as coisas. 9. ed. São Paulo: Martins Fontes, 2007.

. História da sexualidade I: a vontade do saber. Rio de Janeiro: Edições Graal, 1988.

GARRAMUÑO, F. Frutos estranhos: sobre a inespecificidade na estética contemporânea. Trad. Carlos Nogué. Rio de Janeiro: Rocco, 2014. . La literatura en un campo expansivo y la disciplina del comparatismo. Cadernos de estudos culturais, Campo Grande, p. 1-11, 2009. 
GROSSMAN, E. Corpos hipersensiveis: para além da diferença dos sexos. Trad. Ana Kiffer. Rio de Janeiro: Zazie ediçóes, 2016.

KLINGER D. Escritas de si, escritas do outro: o retorno do autor e a virada etnográfica. 2. ed. Rio de Janeiro: 7Letras, 2012.

KRAUSS, R. A escultura no campo ampliado. Arte \& Ensaios, Rio de Janeiro, n.17, p. 128-137, 2008.

LADDAGA, R. Estética de la emergencia: la formación de otra cultura de las artes. Buenos Aires: Adriana Hidalgo, 2006.

LUDMER, J. Literaturas posautónomas. Ciberletras - Revista de crítica literaria y de cultura, n. 17, 2007. Disponível em: <http://www. lehman.cuny.edu/ciberletras/v17/ludmer.htm>. Acesso em: 10 ago. 2010 .

. Notas para Literaturas posautónomas III. 2010. Disponível em: <http://josefinaludmer.wordpress.com/2010/07/31/notas-para-literaturas-posautonomas-iii/>. Acesso em 20 de ago. 2014.

NEGRI, A.; HARDT, M. Value and Affect. Boundary 2, v. 26, n. 2, p. 77-88, 1999.

PAZ, O. Os filhos do barro. Trad. Olga Zavary. Rio de Janeiro: Nova Fronteira, 1984.

RANCIÈRE, J. A partilha do sensivel. São Paulo: EXO Experimental. Org. Ed. 34, 2005.

. Será que a arte resiste a alguma coisa? In: LINS, D. (org.). Nietzsche, Deleuze, arte, resistência. Rio de Janeiro: Editora Forense Universitária, 2007. p. 126-140.

ROSEnBERG, H. A tradição do novo. Trad. de Cezar Tozzi. São Paulo: Perspectiva, 1974.

SARDUY, S. Cobra. In: GUERRERO, G.; WAHL, F. (ed.). Severo Sarduy: obra completa (tomo I). São Paulo: ALLCA XX, 1999. p. 425-584.

. Escrito sobre un cuerpo. In: GUERRERO, G.; WAHL, F. (ed.). Severo Sarduy: obra completa (tomo II). São Paulo: ALLCA XX, 1999. p. 1119-1194.

SUSSEKIND, F. Objetos verbais não identificados. $O$ Globo, 21 set. 2013. Disponívelem: <http://oglobo.globo.com/blogs/prosa/ posts/2013/09/21/objetos-verbais-naoidentificados-um-ensaio-de-flora-sussekind-510390.asp>. Acesso em 21 set. 2013. 
Wanderlan Alves é Doutor em Letras pela Universidade Estadual Paulista (Unesp - São José do Rio Preto). Atualmente é professor de Literatura Hispano-americana da Universidade Estadual da Paraíba (UEPB) e atua no Programa de Pós-graduação em Literatura e Interculturalidade. Dedica-se aos estudos de narrativa moderna e contemporânea latino-americana (tanto hispano-americana quanto brasileira), hibridismos escriturais, literatura e mass media e debates em teoria e crítica contemporâneas sobre novos modos de conceber e ler o literário (pós-autonomia, inespecificidade, dispersão etc.). Coordena o Grupo de Estudos de Literatura e Críticas Contemporâneas - GELCCO (UEPB/CNPq) e é membro da Associação Brasileira de Hispanistas e Latin American Studies Association. E-mail: alveswanderlan@yahoo.com.br

Recebido em: 23/04/2018

Aceito em: 30/07/2018 